\title{
Adhesion of monocytes and endothelial cells isolated from the human aorta suppresses by miRNA-PEI particles
}

\author{
Adeleh Poursaleh ${ }^{1}$, Farnaz Sadegh Beigee ${ }^{2}$, Golnaz Esfandiari ${ }^{1}$ and Mohammad Najafi ${ }^{*}$
}

\begin{abstract}
Background: Knowledge of stenosis in coronary arteries requires an understanding of the cellular and molecular processes that occur throughout the leukocyte rolling process. In this study, the roles of miR-125a-5p and miR-495-3p were investigated on the adhesion of endothelial cells (ECs) isolated from the human aorta.

Methods: Human primary endothelial cells were obtained from the aorta of people who had died of brain death. Whole blood was used to isolate the monocytes. The miR-125 and miR-495 were predicted and transfected into ECs using Poly Ethylene Imine (PEI). The expression levels of adhesion molecules and monocyte recruitment were identified by the RT-qPCR technique and Leukocyte-Endothelial Adhesion Assay kit, respectively.

Results: The ICAM-1, ICAM-2 and VCAM-1 expression levels decreased significantly in the miR-495/PEl-transfected ECs $(P<0.05)$ while in the miR-125/PEI-transfected ECs only the ICAM-2 and ITGB-2 expression levels decreased significantly $(P<0.05)$ as compared to the miR-synthetic/PEl-transfected ECs. Furthermore, the monocyte adhesion was decreased in the miR-125 and miR-mix/PEl-transfected ECs as compared to the miR-synthetic/PEl-transfected ECs ( $P=0.01$ and $P=0.04$, respectively).
\end{abstract}

Conclusion: According to the findings, the efficient relations between miR-125 and adhesion molecules may be responsible for the inhibition of monocyte rolling.

Keywords: Endothelial cell, miR-125, miR-495, ICAM-1, ICAM-2, ITGB-2, VCAM-1

\section{Introduction}

Atherosclerosis is the leading cause of death from cardiovascular diseases (CVD) worldwide [1, 2]. In addition to the influence of lifestyle, several artery cellular dysfunctions are linked to the development of atherosclerosis [3]. The sub-endothelial macrophages, vascular smooth muscle cells (VSMCs), and endothelial cells (ECs) are the most important agents involved in the initiation and progression of atherosclerotic plaques in the heart arteries $[4,5]$. Furthermore, the degree of cellular dysfunction

\footnotetext{
*Correspondence: nbsmmsbn@iums.ac.ir

${ }^{1}$ Biochemistry Department, Microbial Biotechnology Research Center,

Iran University of Medical Sciences, Tehran, Iran

Full list of author information is available at the end of the article
}

is mediated by inflammatory events. The endothelial cells of arterial vessels trigger the leukocyte rolling process through the adhesion molecules. After the entrance of leukocytes mainly monocytes and $\mathrm{T}$ lymphocytes, immune-attractant and chemo-attractant reactions follow the progressive occurrences for the formation of atherosclerotic plaques in vessel sub-endothelial space causing the vessel micro-anatomical alterations and developing the extracellular matrix remodeling events [6]. The thrombotic problems during the progression of the atherosclerosis process may arise plaque ruptures led to vessel stenosis [7-9]. Many molecular and genetic studies have found that certain regulatory abnormalities in cellular signaling pathways lead to atherosclerosis. 
It is well known that miRNAs regulate the function of vascular smooth muscle cells (VSMCs) and modulate the inflammatory responses in vascular endothelial cells so that these events affect vessel stenosis and restenosis [10-13]. Moreover, the miRNAs have been discovered as potential therapeutic targets and clinical biomarkers in coronary artery diseases [14]. In VSMCs, miRNAs influence gene expression levels and control cellular signaling pathways [15-22]. A review of the roles of miRNAs in endothelial cell homeostasis has been published [23]. The miRNAs are also said to have many roles in the functional balance of vascular endothelial cells and circulating leucocytes via biological pathways and inflammatory responses [24].

According to the aforementioned descriptions, adhesion molecules facilitate leukocyte recruitment via the rolling process, which is a crucial phase in vascular stenosis and restenosis [25, 26]. Moreover, many studies also suggested that miRNAs influence the gene expression levels of adhesion molecules [27]. Based on miRNA-related databases, we projected miR-125a-5p and miR-495-3p and examined their impacts on ICAM1, ICAM2, VCAM1, and ITGB2 gene expression levels isolated from human aortic endothelial cells.

\section{Materials and methods}

\section{Tissue sample}

The normal aortic samples were collected postmortem from individuals with brain death by a specialist physician from the Organ Procurement Unit (Masih Daneshvari Hospital) (Subjects aged 21-54y were independently followed all steps; repeats, 3). The samples were submerged in saline/Amphotericin B $(0.25 \mu \mathrm{g} / \mathrm{ml}) /$ Gentamicin (50 mg/ml)/Pen-Strep (\%6, Gibco, Lot: 1697549) solution [28], and were safely transported into the central lab. The aorta's endothelial cells were quickly isolated on ice. The study has been authorized by the university's ethics committee (IR.IUMS.REC 1395.9274).

\section{Human aortic endothelial cell isolation}

A saline solution was used to cleanse the inner and outer surfaces of the aorta (length $8-10 \mathrm{~cm}$ ). The two vessel sides were clamped after filling the aorta with PBS buffer (containing collagenase D 0.2\%, Cat. No. C5138-100MG; Sigma Aldrich). Then, it was incubated for $30 \mathrm{~min}\left(37^{\circ} \mathrm{C}\right.$, $5 \% \mathrm{CO} 2$ ). The inner portion of the aorta was washed with free-serum Endothelial Cell Growth Medium MV (EGMMV, PromoCell, C-22022) several times and the released endothelial cells (ECs) were collected in microtube (Fig. 1). The aorta's endothelial cell pellet was prepared by centrifugation technique ( $2500 \mathrm{rpm}, 7 \mathrm{~min}$ ), and was immediately seeded on the serum-EGM-MV medium (containing ECG complement, ECGS/H $0.004 \mathrm{ml} / \mathrm{ml}$,
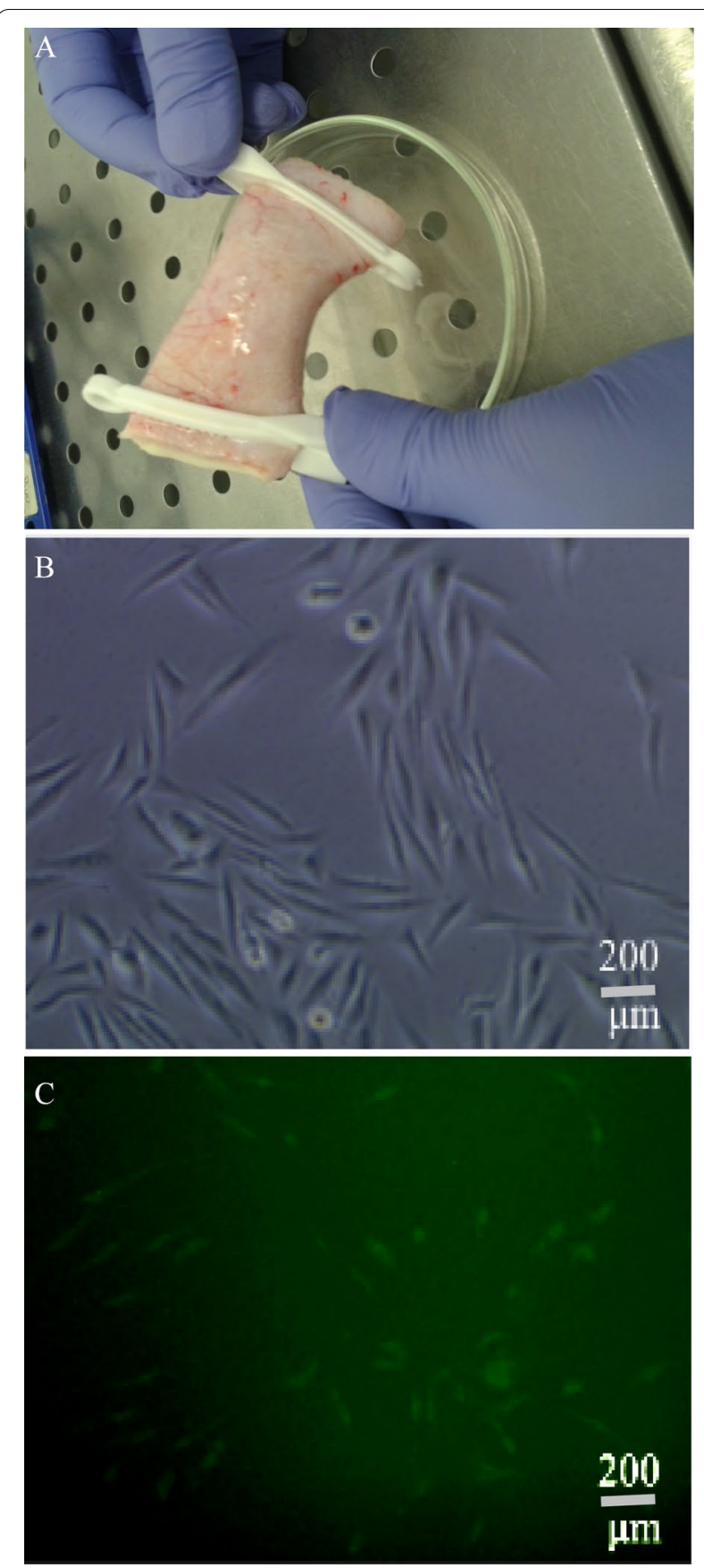

Fig. 1 Isolation of endothelial cells from the human aorta. a The filled and clamped vessel with PBS buffer. b Endothelial cells. c FITC-miRNA/PEl-transfected complex to endothelial cells

hEGF $50 \mu \mathrm{g}$, HC $500 \mu \mathrm{g}$, FCS 5\%, Pen-Strep $1 \%$ and amphotericin B $(0.25 \mu \mathrm{g} / \mathrm{ml}))$. The endothelial cells (ECs) were trypsinized after 7 days. The cellular contents were centrifuged (2500 rpm, $5 \mathrm{~min}$ ), and re-sedimented with cold PBS buffer (containing 10\% FBS, Gibco ${ }^{\mathrm{TM}} 10091148$ ). The cells were washed twice with cold PBS (5 min) and 
finally, the CD31 ${ }^{+}$cells were counted up to $56.7 \%$ using Flow Cytometry.

\section{LPS treatment}

The aorta's endothelial cells isolated from aortic samples were quickly cultured on 6-well plates. The cellular groups were generally pretreated with $10 \mu \mathrm{g} / \mathrm{ml}$ LPS and were passaged three times depending on cell confluency $(\approx 70 \%$ ) (Cat. No.: L6529-1MG; Sigma Aldrich, Korea; Lipopolysaccharides from Escherichia coli 055:B5) for $6 \mathrm{~h}$ $[29,30]$.

\section{Gene and miRNA predictions}

The genes implicated in the EC-leukocyte rolling process were obtained from network-based reactome (https:// reactome.org) and text-based PubMed. STRING (https:// string-db.org) was used to find the gene relationships based on the network edges. The genes were chosen through the network topology, high-evidence and highexpress edges (Score $>0.9$ ) obtained by Cytoscape software. Then, gene-related miRNAs were predicted from miRWalk server (http://zmf.umm.uni-heidelberg.de/ apps/zmf/mirwalk2). The database reports were utilized as edge scores to hit gene-miRNA relationships.

\section{miRNA/PEI particles}

The miRNA transfection was performed using Poly Ethylene Imine (PEI, Cat. No.: BCBS2233V). A solution of PEI $(20 \mathrm{mg} / \mathrm{ml}$ DEPC water) was prepared with shaking at $37^{\circ} \mathrm{C}$. Also, a solution of each miRNA (including has-miR125a-5p TCCCTGAGACCCTTTAACCTG TGA, has-miR495-3p AAACAAACATGGTGCACT TCTT, miRsynthetic CCCGAGACCCAACTGGTC $A C C$ and miR-mix (containing equal amounts from miR125, miR495 and miRsynthetic) $(100 \mathrm{pM})$ was prepared and incubated at room temperature for $20 \mathrm{~min}$ [31]. Then, $1 \mu \mathrm{l}$ of each solution was added to 200 DEPC water and finally, the mixture was added into $800 \mu \mathrm{l} \mathrm{cul-}$ ture medium. Based on the previous studies, the miRNA transfection rate was estimated up to $70 \%$ [16].

\section{EC transfection}

After preheating the cells with LPS, the ECs were transfected with miRNA/PEI particles for $4 \mathrm{~h}$. Finally, the cells were washed in PBS and were cultured in the serumEGM-MV medium for $20 \mathrm{~h}$.

\section{Monocyte isolation}

Human monocytes were isolated using the RosetteSep kit (STEMCELL Technologies) [31]. Tetramer antibodies were added to the whole blood samples according to the producer's procedure. The mixture was diluted with PBS buffer (volume ratio 1:1) and was centrifuged (3000 rpm, $20 \mathrm{~min})$ with a ficoll gradient after incubation $\left(37^{\circ} \mathrm{C}\right.$, $20 \mathrm{~min}$ ). Then, the monocytes were washed in a PBS buffer containing $2 \%$ fetal bovine serum.

\section{RNA extraction and CDNA synthesis}

AccuPrep ${ }^{\circledR}$ Universal RNA Extraction Kit (Bioneer, Korea) was used to extract total RNA from PEI/miRtransfected ECs according to the manufacturer's instructions. Briefly, the endothelial cells were washed with cold PBS three times and, were harvested in lysis buffer $(400 \mu \mathrm{l})$. After adding other buffers, ultimately the RNA sample was extracted and kept at $-80{ }^{\circ} \mathrm{C}$. The cDNA synthesis was carried out using cDNA synthesis kit (Cat. No.: RR037A; Takara, Japan) according to the producer's instructions.

\section{Real-time qPCR method}

The gene expression levels were measured using $A B$ Applied Biosystems stepOne Real-Time PCR systems. The gene expression values were determined with SYBER Green PCR Kit (Cat. No.: RR820Q, Takara, Japan). In each reaction $(15 \mu \mathrm{l})$, the forward and reverse primers (each $0.5 \mu \mathrm{M})$, cDNA $(1 \mu \mathrm{l})$, and master mix $(10 \mu \mathrm{l})$ were used to amplify the gene cDNA samples. The primers were designed using the Primer-BLAST tool. Furthermore, the beta-actin (ACTB) gene was applied as an internal reference (Table 1$)$. The reaction cycles $(n=45)$ for all genes were followed after initial incubation at $94{ }^{\circ} \mathrm{C}$ for $2 \mathrm{~min}, 94^{\circ} \mathrm{C}$ for $30 \mathrm{~s}, 67^{\circ} \mathrm{C}$ (ICAM-1, ICAM -2

Table 1 Primers

\begin{tabular}{llll}
\hline Primer & Forward-primer & Reverse-primer & $\begin{array}{l}\text { Annealing } \\
\text { temperature } \\
\left({ }^{\circ} \mathbf{C}\right)\end{array}$ \\
\hline ICAM-1 & CAGTCAGTGTGACCGCAGAG & CGCCGGAAAGCTGTAGATGG & 67 \\
ICAM-2 & GTCAGCGTGACCAGCCTC & TCATTGCCACGGAACAGGAA & 67 \\
VCAM-1 & CACAGGATTTTCGAGCAGG & 55 \\
ITGB-2 & TGTCAATGTGCCCCCAGA & CCACACACTCTCGGCTCTC & 67 \\
B-ACT & CTGTCGAACAACCCCGTGA & CAAACAAATAAAGCCATGCCAATC & 63 \\
\hline
\end{tabular}


and ITGB-2), $63{ }^{\circ} \mathrm{C}$ (ACTB) and $55^{\circ} \mathrm{C}$ for (VCAM-1) for $30 \mathrm{~s}$.

\section{Immunofluorescence method}

The aorta's endothelial cells $(n=100,000)$ were cultured for $72 \mathrm{~h}$ on 96 -well plates. The cells were then pretreated with LPS $(10 \mu \mathrm{g} / \mathrm{ml}, 6 \mathrm{~h})$, washed with PBS (twice), and transfected by miRNA/EPI particles $(4 \mathrm{~h})$. Afterward, the cells were washed with PBS (twice) and were grown for $20 \mathrm{~h}$. The ligand/LeukoTracker (No. 12101, Cell Biolabs) solution of CytoSelect ${ }^{\mathrm{TM}}$ Leukocyte-Endothelial Adhesion Assay Kit (Cat. No.: CBA-210; Cell Biolabs; Denmark) was mixed with the isolated monocytes (as described in Seciiont 1.7) and was added to the cell culture for $2 \mathrm{~h}$. Then, the cellular mixture was lysed (No. 10404, Cell Biolabs), stirred slowly, and finally the surface monocyte-EC interacted proteins were measured using a fluorescence plate reader $(480 \mathrm{~nm} / 520 \mathrm{~nm})$.

\section{Statistical analysis}

Data were analyzed statistically using a statistical software package (SPSS 24, Chicago). The gene expression levels were calculated using $2^{-\Delta \Delta C T}$ formula. The Kolmogorov-Smirnov test was used to examine the data distribution. The differences between groups were evaluated by ANOVA and t-student tests. $P$ values less than 0.05 were determined to be significant.

\section{Results}

miR-125a-5p and miR-495-3p are predicted for adhesion molecule genes

The high-score genes found using STRING and were subjects for the gene networking (node 23, edge 59). Based on the network topology, the genes of close together (yellow circular nodes, 4) searched to find high-report miRNAs. The miRNAs were added to the gene network so that the miR-125a-5p and miR-495-3p were chosen on the high-score edges (dark edge) (Fig. 2).

\section{miR-495 decreases ICAM-1 gene expression}

The ICAM-1 gene expression level decreased significantly in the miR-495/PEI-transfected ECs as compared to miRsynthetic/PEI-transfected ECs ( $p 0.03)$. The results were not significant for miR-125 and miR-mix/PEI-transfected ECs ( $p 0.82$ and $p 0.39$, respectively) (Fig. 3a).

miR-125 and miR-495 decrease ICAM-2 gene expression The results showed that the ICAM-2 gene expression levels decrease significantly in miR-125 and miR-495/ PEI-transfected ECs as compared to miR-synthetic/

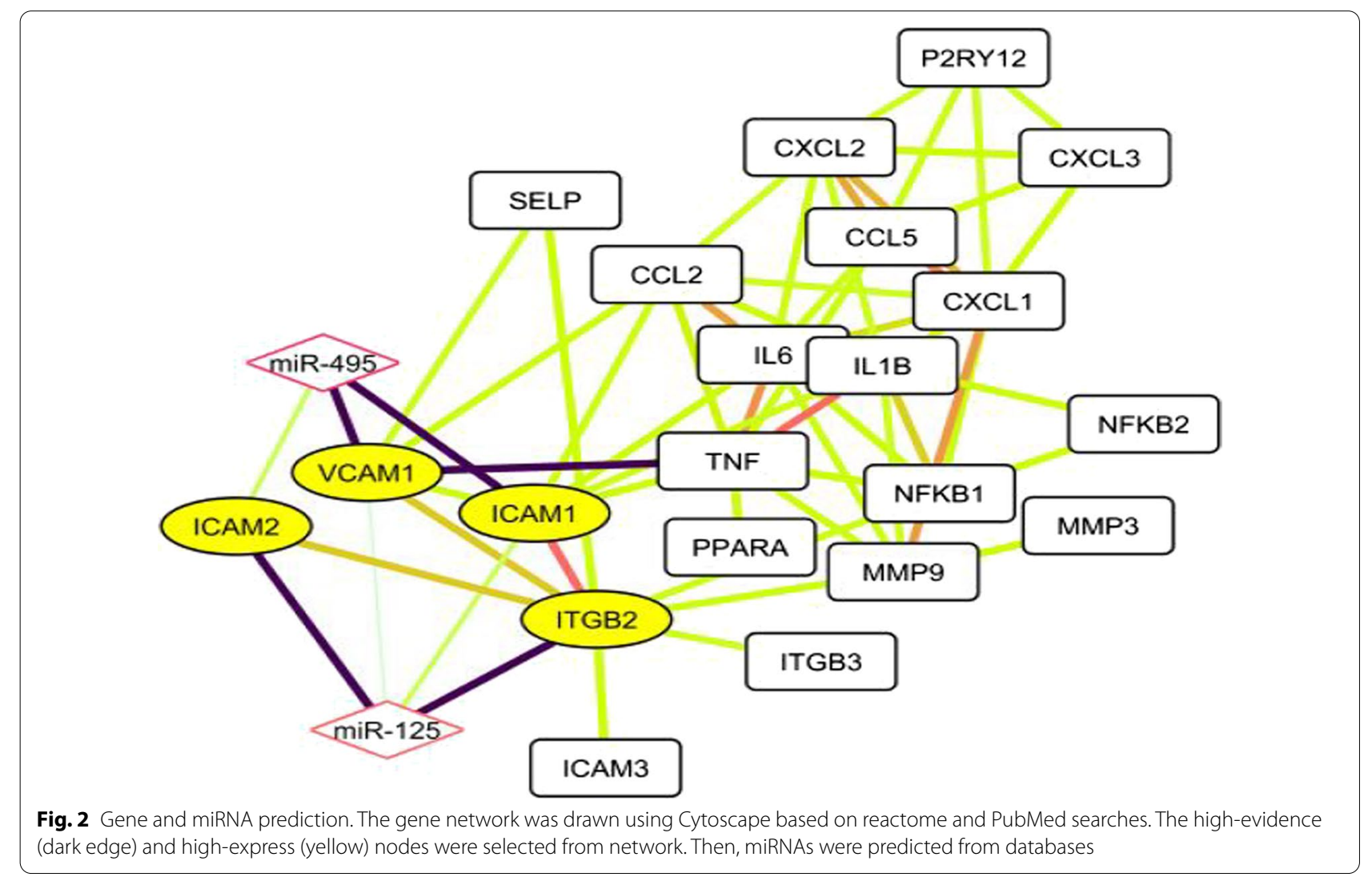




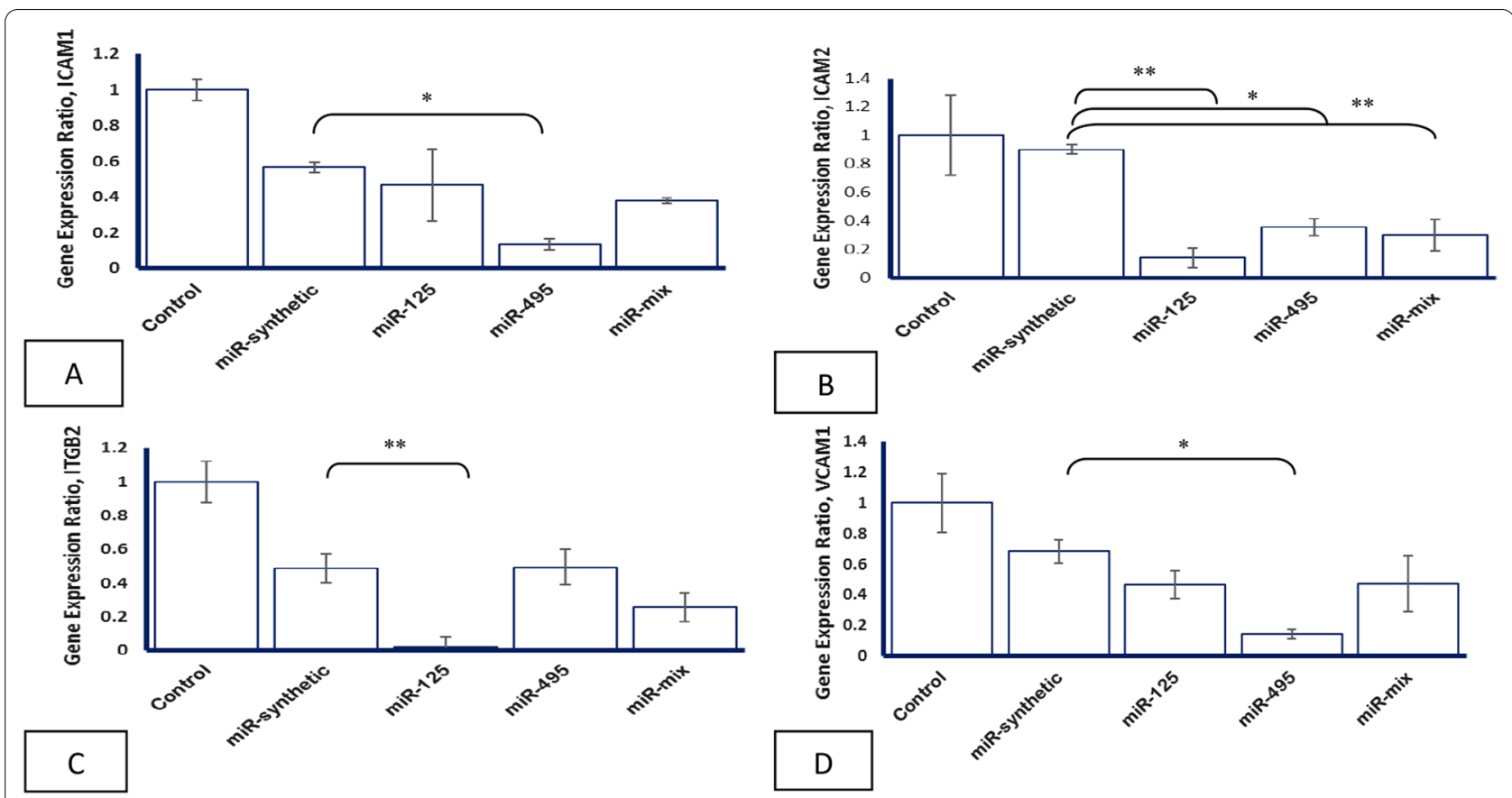

Fig. 3 Effects of miRNA/PEI particles on the gene expression levels. a ICAM1. b ICAM2. c ITGB2. d VCAM1. The data are presented as means \pm SD. ${ }^{*}<0.05,{ }^{* *}<0.005$

PEI-transfected ECs about ten and three times, respectively ( $p 0.004$ and $p 0.012$, respectively). Furthermore, the ICAM-2 gene expression decreased in the miR-mix/ PEI-transfected ECs ( $p$ 0.009) (Fig. 3b).

\section{miR-125 decreases ITGB-2 gene expression}

The ITGB-2 gene expression level decreased in miR-125/ PEI-transfected ECs as compared to miR-synthetic/PEItransfected ECs $(p$ 0.001). However, the ITGB-2 gene expression level was not decreased significantly in the miR-495 and miR-mix/PEI-transfected ECs ( $p 0.9$ and $p$ 0.20 , respectively) (Fig. 3c).

\section{miR-495 decreases VCAM-1 gene expression}

The results showed that the VCAM-1 gene expression level decreases in miR-495/PEI- transfected ECs as compared to miR-synthetic/PEI-transfected ECs ( $p$ 0.02) (Fig. 3d).

\section{miR-125 and miR-mix decrease monocyte-endothelial cell adhesion}

miR-495 had no significant effect on the endothelialmonocyte cell adhesion ( $p$ 0.86). The adhesion molecule protein values decreased significantly in the miR-125 and miR-mix/PEI- transfected ECs ( $p 0.04$ and $p 0.01$, respectively) as compared to miR-synthetic/PEI-transfected ECs (Fig. 4).

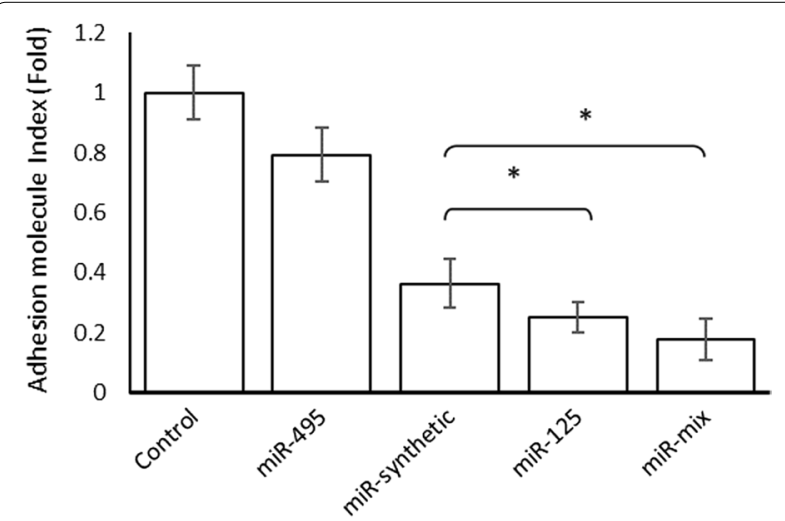

Fig. 4 Adhesion molecule protein expression index. The adhesion rate between ECs and monocytes reduced for miR-125 and miR-mix as compared with miR-synthetic. ${ }^{*}<0.05$

\section{Discussion}

The cellular responses of the vascular wall during the atherosclerosis process relate to the adhesion molecule functions, inflammatory events, lipid dysregulation, and extracellular remodeling dysfunction. Since the vessel restenosis is known as the most common problem following stenting thus studies on the cellular mechanisms involved in this process are of interest. It is well known that miRNAs change the extracellular and cellular proteomes via regulation of genes involved in the 
cellular signaling pathways. Since the polarization of macrophages and their roles in the progression of atherosclerosis plaques relate to monocyte rolling process thus the adhesion molecules presented on the surface of ECs are the most important miRNA-regulated gene targets that effectively affect the entrance of monocytes into subendothelial spaces [32-37]. There were the reports on circulating miRNAs as potential markers of the monocyte rolling and atherosclerosis events [38-41]. In this study, the effects of miR-495 and miR-125 on adhesion molecule genes (ICAM-1, ICAM-2, ITGB-2, and VCAM1) were examined on the basis of prediction data in aortic endothelial cells.

Some studies suggested that miR-125 is expressed in ECs and VSMCs, and is closely linked to the activities of some cellular signaling pathways. In stroke-prone spontaneously hypertensive rats, miR-125 has been postulated as a key therapeutic component [42]. It was also reported as a cellular modulator [43], suppressing miR125a-5p, which led to PDGF-induced VSMC proliferation and migration [44]. Furthermore, other studies have found that the miR-125a-5p modulates the PI3K/Akt/ eNOS pathway, as well as apoptosis, inflammation, and mediates vasculoprotective effects in the endothelial cells [45-47]. Our study showed that the miR-125/PEI-transfected endothelial cells decrease the ICAM-2 and ITGB-2 expression levels. Furthermore, their ability for adhesion into monocytes was decreased, suggesting that adhesion molecule expression levels are primarily influenced by miR-125.

Furthermore, miR-495 has been shown to suppress tumor cell proliferation, migration, and invasion [48-51]. It is also important in the development of pluripotent stem cells into endothelial cells [52]. According to several studies, miR-495 reduces inflammatory events by inhibiting the inflammasome signaling pathway [53] and may act as a tumor suppressor by directly targeting PIK3R1 gene in endometrial cancer cells [54]. Moreover, the inhibition of miR-495 improved pulmonary vascular structural changes in mice [55]. The miR-495 also induced potent cardiomyocyte proliferation due to suppression of coactivator Cited 2 factor [56]. Furthermore, the miR495 suppressed CCL2 expression and inhibited the EC proliferation and migration pathways [57-61]. Our study showed that the ICAM-1, ICAM-2, and VCAM-1 expression levels are suppressed in the miR-495/PEI-transfected aortic endothelial cells. The EC-monocyte cell adhesion levels also changed but not significantly in these cells. Based on the results of miR-mix/PEI-transfected aortic endothelial cells, this study suggested that the functional effect of a miRNA might be related cumulatively to other miRNAs in the cells. Furthermore, it is proposed that the cellular uptake and clearance of miRNA mixtures may be related to the numbers and sequences of delivered miRNAs in ex-vivo mRNA expression evaluations.

\section{Conclusion}

The ICAM-1, ICAM-2, and VCAM-1 expression levels are related to miR-495. There were expression associations between the ICAM-2, ITGB-2, and miR-125. Furthermore, monocyte adherence to miRNA-transfected aortic endothelial cells confirmed the role of miR-125 and the cumulative effects of miR-495 on cellular adhesion, showing that miRNAs may inversely control leukocyte rolling process. The use of miRNAs may improve the effectiveness of drug-based approaches [62] in the treatment of vessel stenosis and re-stenosis. These components can develop the controlled drug delivery techniques in drug-eluting stents and drug-eluting balloons [63]. However, it was better to study the roles of miRNAs in vessel scaffolds to improve our understanding from diapedesis process.

\section{Authors' contributions \\ $M N$, designed research; AP, FSB, and GE performed experiments; MN, AP, and GE analyzed data; MN and AP wrote the manuscript. All authors reviewed and approved the manuscript. \\ Funding \\ The study is supported by Iran University of Medical Sciences, Grant No. 93-03-30-29274. \\ Availability of data and materials \\ The data used and analyzed in this study are presented by the corresponding author on request.}

\section{Declarations}

Ethics approval and consent to participate

The Ethical Committee of Iran University of Medical Sciences, Tehran, Iran, approves the study (29274). The informed consent was obtained from families of subjects with brain death. Moreover, an informed consent was obtained from participants given monocyte samples. All procedures performed in studies involving human participants were in accordance with the ethical standards of the institutional research committee with the 1964 Helsinki declaration. Ethical approval was obtained for the monocyte isolation from healthy subjects.

\section{Competing interests \\ The authors declare no competing interests.}

\section{Author details}

${ }^{1}$ Biochemistry Department, Microbial Biotechnology Research Center, Iran University of Medical Sciences, Tehran, Iran. ${ }^{2}$ Masih Daneshvari Hospital, Shahid Beheshti University of Medical Sciences, Tehran, Iran.

Received: 14 June 2021 Accepted: 7 August 2021

Published online: 16 August 2021

References

1. Ross R. The pathogenesis of atherosclerosis - an update. N Engl J Med. 1986;314(8):488-500. 
2. Dahlöf B. Cardiovascular disease risk factors: epidemiology and risk assessment. Am J Cardiol. 2010;105(1):3A-9A.

3. Libby P, Ridker PM, Hansson GK. Progress and challenges in translating the biology of atherosclerosis. Nature. 2011;473(7347):317.

4. Glass CK, Witztum JL. Atherosclerosis. Cell. 2001;104(4):503-16.

5. Libby P, Ridker PM, Maseri A. Inflammation and atherosclerosis. Circulation. 2002;105(9):1135-43.

6. Tabas I, Williams KJ, Borén J. Subendothelial lipoprotein retention as the initiating process in atherosclerosis: update and therapeutic implications. Circulation. 2007;116(16):1832-44.

7. Chistiakov DA et al. Human miR-221/222 in physiological and atherosclerotic vascular remodeling. In: BioMed research international, 2015.

8. Volný $\mathrm{O}$ et al. microRNAs in cerebrovascular disease microRNA. In: Medical evidence. 2015, Springer, pp. 155-195.

9. Ross R. Atherosclerosis_-an inflammatory disease. N Engl J Med. 1999:340:115-26.

10. Nugent M. MicroRNA function and dysregulation in bone tumors: the evidence to date. Cancer Manag Res. 2014;6:15.

11. Bartel DP. MicroRNAs: genomics, biogenesis, mechanism, and function. Cell. 2004:116(2):281-97.

12. Bartel DP. MicroRNAs: target recognition and regulatory functions. Cell. 2009;136(2):215-33.

13. Chen LJ, Lim SH, Yeh YT, Lien SC, Chiu JJ. Roles of microRNAs in atherosclerosis and restenosis. J Biomed Sci. 2012;19(1):79. https://doi.org/10. 1186/1423-0127-19-79.

14. Solly EL, Dimasi CG, Bursill CA, Psaltis PJ, Tan JTM. MicroRNAs as therapeutic targets and clinical biomarkers in atherosclerosis. J Clin Med. 2019;8(12):2199.

15. Ghasempour G, Mohammadi A, Zamani-Garmsiri F, Najafi M. miRNAs through beta-ARR2/p-ERK1/2 pathway regulate the VSMC proliferation and migration. Life Sci. 2021;279:119703.

16. Ghasempour G, Mahabadi VP, Shabani M, Mohammadi A, ZamaniGarmsiri F, Amirfarhangi A, Karimi M, Najafi M. miR-181b and miR-204 suppress the VSMC proliferation and migration by downregulation of HCK. Microvasc Res. 2021;2021136:104172.

17. Rayner KJ, Moore KJ. The plaque "micro" environment: microRNAs control the risk and the development of atherosclerosis. Curr Atheroscler Rep. 2012;14(5):413-21.

18. Yang $Y$, et al. MicroRNA-155 promotes atherosclerosis inflammation via targeting SOCS1. Cell Physiol Biochem. 2015;36(4):1371-81.

19. Madrigal-Matute J, et al. MicroRNAs and atherosclerosis. Curr Atheroscler Rep. 2013;15(5):322

20. Suárez Y, et al. Dicer dependent microRNAs regulate gene expression and functions in human endothelial cells. Circ Res. 2007;100(8):1 164-73.

21. Zuo K, et al. A dysregulated microRNA-26a/EphA2 axis impairs endothelial progenitor cell function via the p38 MAPKVEGF pathway. Cell Physiol Biochem. 2015;35(2):477-88.

22. Chamorro-Jorganes A, Araldi E, Suárez Y. MicroRNAs as pharmacological targets in endothelial cell function and dysfunction. Pharmacol Res. 2013;75:15-27.

23. Fernández-Hernando C, Suárez Y. MicroRNAs in endothelial cell homeostasis and vascular disease. Curr Opin Hematol. 2018;25(3):227-36.

24. Kakavandi N, Rezaee S, Hosseini-Fard SR, Ghasempour G, Khosravi M, Shabani M, Najafi M. Prostaglandin E2 (PGE2) synthesis pathway is involved in coronary artery stenosis and restenosis. Gene. 2021;765:145131.

25. Springer TA. Adhesion receptors of the immune system. Nature. 1990;346(6283):425

26. Davies MJ, et al. The expression of the adhesion molecules ICAM-1, VCAM-1, PECAM, and E-selectin in human atherosclerosis. J Pathol. 1993;171(3):223-9.

27. Churov A, Summerhill V, Grechko A, Orekhova V, Orekhov A. MicroRNAs as Potential Biomarkers in Atherosclerosis. Int J Mol Sci. 2019:20(22):5547.

28. Poursaleh A, Esfandiari G, Sadegh Beigee F, Eshghifar N, Najafi M. Isolation of intimal endothelial cells from the human thoracic aorta: study protocol. Med J Islam Repub Iran. 2019;4(33):51.

29. Matsushita K, et al. Lipopolysaccharide enhances the production of vascular endothelial growth factor by human pulp cells in culture. Infect Immun. 1999:67(4):1633-9.

30. Heidarzadeh M, Avcı ÇB, Saberianpour S, Ahmadi M, Hassanpour M, Bagheri HS, Rezaie J, Talebi M, Roodbari F, Sokullu E, Darabi M, Rahbarghazi R. Activation of toll-like receptor signaling in endothelial progenitor cells dictates angiogenic potential: from hypothesis to actual state. Cell Tissue Res. 2021;384(2):389-401.

31. Hassanpour P, et al. Interleukin 6 may be related to indoleamine 2, 3-dioxygense function in M2 macrophages treated with small dense LDL particles. Gene. 2017;626:442-6.

32. McDonald RA, et al. Reducing in-stent restenosis: therapeutic manipulation of miRNA in vascular remodeling and inflammation. J Am Coll Cardiol. 2015;65(21):2314-27.

33. Chen L-J, et al. Roles of microRNAs in atherosclerosis and restenosis. J Biomed Sci. 2012;19(1):79.

34. Rafiee L, Hajhashemi V, Javanmard SH. Maprotiline inhibits LPS-induced expression of adhesion molecules (ICAM-1 and VCAM-1) in human endothelial cells. Res Pharmaceut Sci. 2016;11(2):138.

35. Panés J, Perry M, Granger DN. Leukocyte-endothelial cell adhesion: avenues for therapeutic intervention. Br J Pharmacol. 1999;126(3):537-50.

36. Muller WA. Leukocyte-endothelial-cell interactions in leukocyte transmigration and the inflammatory response. Trends Immunol. 2003;24(6):326-33.

37. Li H, et al. Inducible expression of vascular cell adhesion molecule- 1 by vascular smooth muscle cells in vitro and within rabbit atheroma. Am J Pathol. 1993;143(6):1551.

38. He M, et al. Plasma microRNAs as potential noninvasive biomarkers for in-stent restenosis. PLoS ONE. 2014;9(11):112043.

39. Romaine SP et al. MicroRNAs in cardiovascular disease: an introduction for clinicians. Heart, 2015.

40. Shiiba M, et al. MicroRNA-125b regulates proliferation and radioresistance of oral squamous cell carcinoma. Br J Cancer. 2013;108(9):1817.

41. Ghosh AK, et al. Molecular basis of cardiac endothelial-to-mesenchymal transition (EndMT): differential expression of microRNAs during EndMT. Cell Signal. 2012;24(5):1031-6.

42. Li D, et al. MicroRNA-125a/b-5p inhibits endothelin-1 expression in vascular endothelial cells. J Hypertens. 2010;28(8):1646-54.

43. Gareri C, De Rosa S, Indolfi C. MicroRNAs for restenosis and thrombosis after vascular injury. Circ Res. 2016;118(7):1170-84.

44. Zheng X, Wu Z, Xu K, Qiu Y, Su X, Zhang Z, Zhou M. Interfering histone deacetylase 4 inhibits the proliferation of vascular smooth muscle cells via regulating MEG3/miR-125a-5p/IRF1. Cell Adh Migr. 2019;13(1):41-9.

45. Pan Q, Ma C, Wang Y, Wang J, Zheng J, Du D, Liao X, Chen Y, Chen Y, Bihl J, Chen C, Yang Y, Ma X. Microvesicles-mediated communication between endothelial cells modulates, endothelial survival, and angiogenic function via transferring of miR-125a-5p. J Cell Biochem. 2019;120(3):3160-72.

46. Chen T, et al. MicroRNA-125a-5p partly regulates the inflammatory response, lipid uptake, and ORP9 expression in oxLDL-stimulated monocyte/macrophages. Cardiovasc Res. 2009;83(1):131-9.

47. Schmitz B, Breulmann FL, Jubran B, Rolfes F, Thorwesten L, Krüger M, Klose A, Schnittler HJ, Brand SM. A three-step approach identifies novel shear stress-sensitive endothelial microRNAs involved in vasculoprotective effects of high-intensity interval training (HIIT). Oncotarget. 2019:10(38):3625-40.

48. Li J-Z, et al. MicroRNA-495 regulates migration and invasion in prostate cancer cells via targeting Akt and mTOR signaling. Cancer Invest. 2016;34(4):181-8

49. Chen $Y$, et al. Demethylation of miR-495 inhibits cell proliferation, migration and promotes apoptosis by targeting STAT-3 in breast cancer. Oncol Rep. 2017:37(6):3581-9.

50. Wang $\mathrm{H}$, et al. MicroRNA-495 inhibits gastric cancer cell migration and invasion possibly via targeting high mobility group AT-hook 2 (HMGA2). Med Sci Monit Int Med J Exp Clin Res. 2017:23:640.

51. Hwang-Verslues W, et al. miR-495 is upregulated by E12/E47 in breast cancer stem cells, and promotes oncogenesis and hypoxia resistance via downregulation of E-cadherin and REDD1. Oncogene. 2011;30(21):2463.

52. Liang J, et al. Inhibition of microRNA-495 enhances therapeutic angiogenesis of human induced pluripotent stem cells. Stem Cells. 2017:35(2):337-50.

53. Zhou T, Xiang DK, Li SN, Yang LH, Gao LF, Feng C. MicroRNA-495 ameliorates cardiac microvascular endothelial cell injury and inflammatory reaction by suppressing the NLRP3 inflammasome signaling pathway. Cell Physiol Biochem. 2018;49(2):798-815.

54. Tan A, Luo R, Ruan P. miR-495 promotes apoptosis and inhibits proliferation in endometrial cells via targeting PIK3R1. Pathol Res Pract. 2019:215(3):594-9. 
55. Fu J, Bai P, Chen Y, Yu T, Li F. Inhibition of miR-495 improves both vascular remodeling and angiogenesis in pulmonary hypertension. J Vasc Res. 2019;56(2):97-106.

56. Clark AL, Naya FJ. miR-410 and miR-495 regulate cardiomyocyte proliferation. 2015.

57. Takeya M, et al. Detection of monocyte chemoattractant protein-1 in human atherosclerotic lesions by an anti-monocyte chemoattractant protein-1 monoclonal antibody. Hum Pathol. 1993;24(5):534-9.

58. Ylä-Herttuala S, et al. Expression of monocyte chemoattractant protein 1 in macrophage-rich areas of human and rabbit atherosclerotic lesions. Proc Natl Acad Sci. 1991;88(12):5252-6.

59. Liu D, et al. MicroRNA-495 regulates the proliferation and apoptosis of human umbilical vein endothelial cells by targeting chemokine CCL2. Thromb Res. 2015;135(1):146-54.

60. Weber KS, et al. Expression of CCR2 by endothelial cells: implications for MCP-1 mediated wound injury repair and in vivo inflammatory activation of endothelium. Arterioscler Thromb Vasc Biol. 1999;19(9):2085-93.
61. Hartmann P, Schober A, Weber C. Chemokines and microRNAs in atherosclerosis. Cell Mol Life Sci. 2015;72(17):3253-66.

62. Sacks D, Baxter B, Campbell BCV, Carpenter JS, Cognard C, Dippel D, Eesa M, Fischer U, Hausegger K, Hirsch JA, Shazam Hussain M, Jansen O, Jayaraman MV, Khalessi AA, Kluck BW, Lavine S, Meyers PM, Ramee S, Rüfenacht DA, Schirmer CM, Vorwerk D. Multisociety consensus quality improvement revised consensus statement for endovascular therapy of acute ischemic stroke. Int J Stroke. 2018;13(6):612-32.

63. Rykowska I, Nowak I, Nowak R. Drug-eluting stents and balloonsmaterials, structure designs, and coating techniques: a review. Molecules. 2020;25(20):4624

\section{Publisher's Note}

Springer Nature remains neutral with regard to jurisdictional claims in published maps and institutional affiliations.
Ready to submit your research? Choose BMC and benefit from:

- fast, convenient online submission

- thorough peer review by experienced researchers in your field

- rapid publication on acceptance

- support for research data, including large and complex data types

- gold Open Access which fosters wider collaboration and increased citations

- maximum visibility for your research: over $100 \mathrm{M}$ website views per year

At $\mathrm{BMC}$, research is always in progress.

Learn more biomedcentral.com/submissions 